\title{
Three Synchronous Primary Lung Cancers in a Single Lobe
}

Erika Simmerman DO ${ }^{1}$, Christy Stover DO², Andrew Simmerman BS ${ }^{2}$, Zhonglin Hao ${ }^{3}$, Daniel Kleven ${ }^{2}$ and Carsten Schroeder ${ }^{1 *}$

${ }^{1}$ Department of Surgery, Thoracic Surgical Oncology, Georgia Regents University, Augusta, GA, USA

${ }^{2}$ Department of Pathology, Georgia Regents University, Augusta, GA, USA

${ }^{3}$ Department of Medicine, Hematology/Oncology, Georgia Regents University, Augusta, GA, USA

\begin{abstract}
As a result of improved cancer detection and greater life expectancy, diagnoses of synchronous primary lung cancers are becoming more common. We present a unique example of three distinctly different histologic tumors in one lobe. A 63 year-old female with suspicious lung nodules opted for short term CT-scan follow-up for two separate right upper lobe (RUL) nodules. In the two months interval a new subcentimeter RUL nodule developed. All three nodules were hypermetabolic on PET-CT. After wedge resection, that revealed a large cell neuroendocrine carcinoma, a formal right upper lobectomy was performed. Pathology revealed: a Sarcomatoid carcinoma, an adenocarcinoma with intracellular mucine, and a large cell neuroendocrine caricnoma.
\end{abstract}

Interestingly, the third tumor was discovered during post-surgical tumor board discussion requesting a reexamination of the lobectomy specimen, emphasizing the importance of multidisciplinary review. This case might indicate that such synchronicities may occur at a greater rate than currently estimated.

Keywords: Synchronous primary lung cancer; Multidisciplinary approach; Tumor board; Lung cancer

\section{Introduction}

As a result of improved cancer detection and greater life expectancy, diagnoses of synchronous primary lung cancers (SPLCs) are becoming more common $[1,2]$, incidence estimates range from $0.2 \%$ to $20 \%$ of non-small cell lung cancers [3-5]. Multiple primary malignancies, with different histologies or similar histologies but clearly distinct histologic features [6], likely call for different treatments than single primary malignancies or multiple tumors from a single origin. However, there is no general consensus on how best to treat these cancers, driving the accumulation of many case studies and retroactive statistical analyses on the topic.

The objective of this case study is to present a unique example of SPLCs in which three distinctly different histologic tumors were detected in one lobe, is currently undocumented in the literature.

\section{Case Report}

A 63-year-old African American female presented to thoracic surgery for workup of suspicious lesions in the right upper lobe (RUL). She was well known to the medicine service from multiple COPD exacerbation admissions and severe emphysema. Past medical history was significant for asthma, diabetes, GERD, and hypertension. She smoked $1 / 4$ PPD for 30 years (quitting at age 59). She had a family history of cancer.

During an admission for COPD exacerbation, a chest X-ray demonstrated a suspicious nodule in the right lung. Multiple axial CTscan images were obtained, revealing a spiculated soft tissue density nodule in the periphery of the RUL (Figure 1A) as well as a second posterior pleural-based lesion (Figure 1B).

The patient opted for a short interval follow-up rather than right out surgery. Repeat CT demonstrated in only two months an interval enlargement of the two separate RUL nodules (Figures 1D and 1E) along with interval development of a new subcentimeter RUL nodule (Figure 1F). PET-CT revealed all three nodules to be hypermetabolic.

A video-assisted thoracoscopic surgery (VATS) wedge resection of the dominant anterolateral nodule was performed and returned on frozen section as large cell neuroendocrine carcinoma. Formal VATS right upper lobectomy with mediastinal lymph node dissection was subsequently performed.

Pathology identified two primary synchronous cancers, but during review of the case at the post-surgical multidisciplinary tumor board the radiologist suggested re-examination of the pathologic specimen to investigate a subcentimeter nodule observed on the repeat CT (Comparing Figures 1C and 1F). Pathology returned to the specimen and was able to locate the additional tumor. Final pathology revealed the following three primary tumors: a large cell neuroendocrine carcinoma (pT2aN1M0, stage IIA, Figure 2A-B), a sarcomatoid carcinoma (pT1bN0M0, stage IA, Figure 2C-D), and a moderately differentiated adenocarcinoma with intracellular mucine (pTlaN0M0, stage IA, Figures $2 \mathrm{E}$ and $2 \mathrm{~F}$ ).

Due to her relatively young age, tumor staging, and N1 status (only intralobar disease), adjuvant chemotherapy was recommended to begin 4 weeks following surgery, with an emphasis on treating the more aggressive neuroendocrine tumor. She started chemotherapy with carboplatin/etoposide, to undergo treatment for a total of 4 cycles. She has tolerated the chemotherapy well to this point.

\section{Discussion}

It is imperative to distinguish between synchronous primary lung cancers and pulmonary metastasis as the prognoses and treatments are different. Multiple primary lung cancers may be synchronous (initial cancer diagnoses occurring within six months of one another) or metachronous (occurring more than six months apart) $[7,8]$, with synchronous tumors reported to be rarer than metachronous tumors [9]. The incidence of synchronous lung carcinomas has been reported

*Corresponding author: Carsten Schroeder, Department of Surgery, Thoracic Surgical Oncology Georgia Regents University, 1120 15th Street Augusta, GA 30912, USA, Tel: 706-721-4726; Fax: 216844 7597; Email: cshroeder@gru.edu

Received March 10, 2015; Accepted March 27, 2015; Published March 29, 2015

Citation: Erika Simmerman DO, Christy Stover DO, Andrew Simmerman BS, Zhonglin Hao, Daniel Kleven, et al. (2015) Three Synchronous Primary Lung Cancers in a Single Lobe. J Clin Case Rep 5: 502. doi:10.4172/2165-7920.1000502

Copyright: (c 2015 Erika Simmerman DO, et al. This is an open-access article distributed under the terms of the Creative Commons Attribution License, which permits unrestricted use, distribution, and reproduction in any medium, provided the original author and source are credited. 


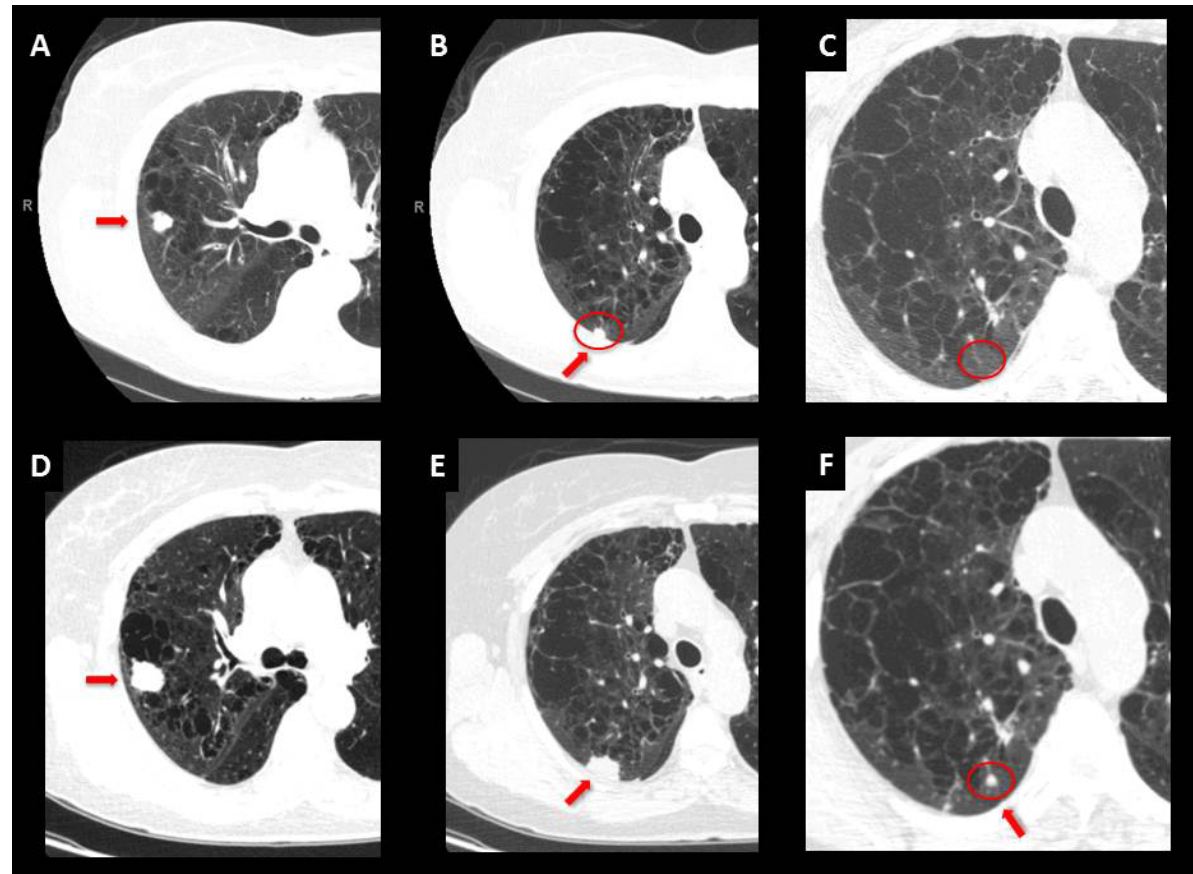

Figure 1: Multiple chest CT-scans. (A): showing an anterolateral RUL $1.3 \mathrm{~cm} \times 1.1 \mathrm{~cm} \times 1.9 \mathrm{~cm}$ spiculated soft tissue density, that increased within 2 months to 2.4 $\mathrm{cm} \times 2.3 \mathrm{~cm} \times 2.1 \mathrm{~cm}$.

(B): Posterior segment RUL pleural-based lesion $0.8 \times 0.5 \mathrm{~cm} \times 1.2 \mathrm{~cm}$, which increased within 2 months to $2.3 \mathrm{~cm} \times 1.3 \mathrm{~cm} \times 1.8 \mathrm{~cm}$.

(C): Histologically an adenocarcinoma with typical intra cellular mucine.

(D): Histologically a large cell neuroendocrine caricnoma.

(E): Histologically a sarcomatoid tumor.

(F): New RUL nodule within the posterior segment measures $0.6 \mathrm{~cm} \times 0.5 \mathrm{~cm}$, which was not present 2 month prior.

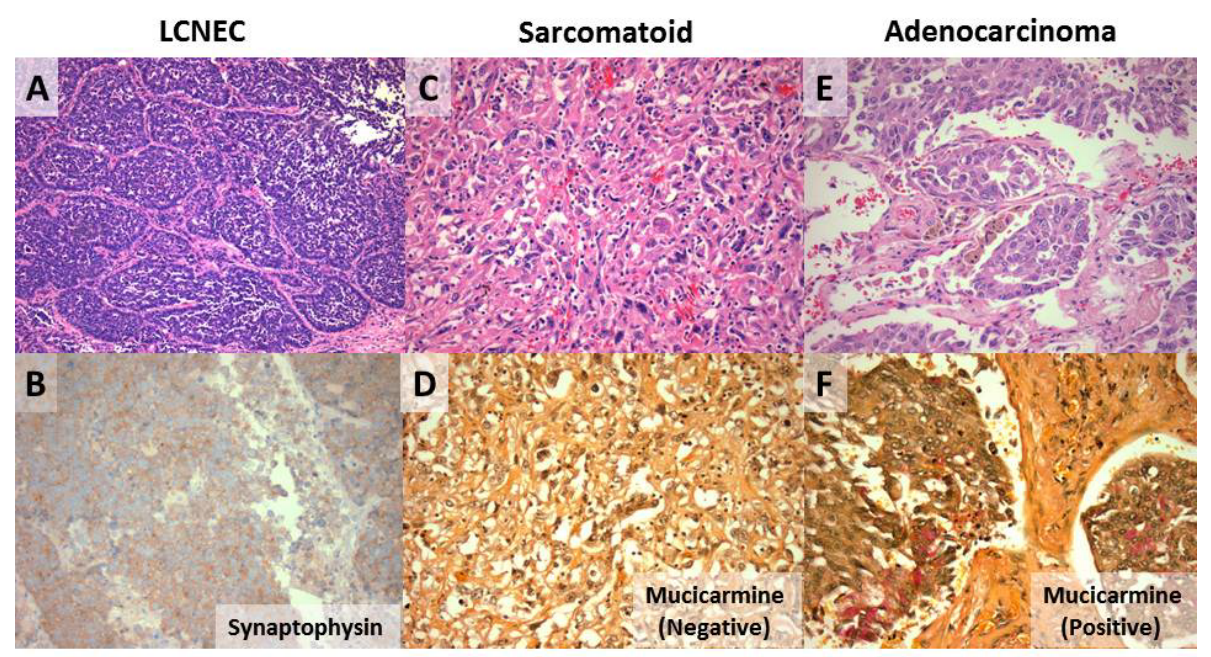

Figure 2: A: LCNEC (large cell neuroendocrine carcinoma): islands of large, uniform cells with round/oval nuclei and scant cytoplasm (H\&E, 100X).

B: Synaptophysin stain: neuroendocrine marker, brown cytoplasmic stain (200X).

C: Sarcomatoid tumor: spindle shaped cells (H\&E, 200X).

D: Mucicarmine stain: negative (a pink cytoplasmic stain to identify adenocarcinoma).

E: Adenocarcinoma: Columnar cells forming glands and producing mucin (H\&E, 200X).

F: Mucicarmine stain: positive pink cytoplasmic stains (200X).

as being between $1 \%$ and $16 \%$ of lung cancer diagnoses [10,11], while reports of the incidence of metachronous primary lung cancers ranges between $40 \%-60 \%$ [10,12].

Finley et al. [3] reported a large series of surgically treated SPLCs, demonstrating overall survival rates comparable with single lung cancers of similar stages. Adenocarcinomas accounted for a majority of synchronous primary lung cancers, with estimates ranging from 75$80 \%[3,7]$. In fact, it seems that a majority of SPLC occurrences include only adenocarcinomas. In general, less than $20 \%$ of SPLC incidences exhibit distinct histologies [3,7]. Recently a case of synchronous triple 
Citation: Erika Simmerman DO, Christy Stover DO, Andrew Simmerman BS, Zhonglin Hao, Daniel Kleven, et al. (2015) Three Synchronous Primary Lung Cancers in a Single Lobe. J Clin Case Rep 5: 502. doi:10.4172/2165-7920.1000502

primary lung cancers in a 72-year-old male was described, who found to have two invasive adenocarcinomas and one squamous carcinoma, but even in this case the tumors were located in different pulmonary lobes [8].

It was therefore very unusual that our patient presented with a stage IIA large cell neuroendocrine caricnoma, a stage IA adenocarcinoma, and a stage IA sarcomatoid carcinoma, all in the right upper lobe.

Interestingly, the third tumor was discovered during post-surgical tumor board discussion, requesting a re-examination of the lobectomy specimen. This emphasizes the importance of multidisciplinary review of cancer cases. Our case might indicate that synchronicities primaries may occur at a greater rate than currently estimated.

\section{References}

1. Spratt JS Jr, Hoag MG (1966) Incidence of multiple primary cancers per manyear of follow up: 20-year review from the Ellis Fischel State Cancer Hospital. Ann Surg 164: 775-784.

2. Sakellakis M, Peroukides S, Iconomou G, Boumpoucheropoulos S, Kalofonos $\mathrm{H}$ (2014) Multiple primary malignancies: a report of two cases. Chin J Cancer Res 26: 215-218.

3. Finley DJ, Yoshizawa A, Travis W, Zhou Q, Seshan VE, et al. (2010) Predictors of outcomes after surgical treatment of synchronous primary lung cancers. J Thorac Oncol 5: 197-205.
4. Adebonojo SA, Moritz DM, Danby CA (1997) The results of modern surgical therapy for multiple primary lung cancers. Chest 112: 693-701.

5. Rea F, Marulli G, Callegaro D, Zuin A, Gobbi T, et al. (2004) Prognostic significance of main bronchial lymph nodes involvement in non-small cell lung carcinoma: N1 or N2? Lung Cancer 45: 215-220.

6. Martini N, Melamed MR (1975) Multiple primary lung cancers. J Thorac Cardiovasc Surg 70: 606-612.

7. Powell S, Tarchand G, Rector T, Klein M (2013) Synchronous and metachronous malignancies: analysis of the Minneapolis Veterans Affairs (VA) tumor registry. Cancer Causes Control 24: 1565-1573.

8. Yoon HJ, Lee HY, Han J, Choi YL (2014) Synchronous triple primary lung cancers: a case report. Korean J Radiol 15: 646-650.

9. Sulkes A, Naparstek Y, Shalit M, Kopolovic J (1980) Second primary lung carcinoma. J Surg Oncol 15: 375-380.

10. Shen C, Wang X, Tian L, Che G (2014) Microsatellite alteration in multiple primary lung cancer. J Thorac Dis 6: 1499-1505.

11. Ferguson MK, DeMeester TR, DesLauriers J, Little AG, Piraux M, et al. (1985) Diagnosis and management of synchronous lung cancers. J Thorac Cardiovasc Surg 89: 378-385.

12. Okada M, Tsubota N, Yoshimura M, Miyamoto $Y$ (1998) Operative approach for multiple primary lung carcinomas. J Thorac Cardiovasc Surg 115: 836-840. 